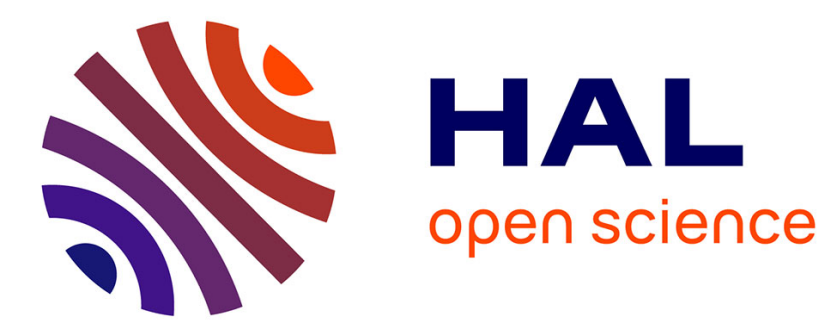

\title{
Ultrasonic Study of Magnetoelastic Effects in the Spin-Peierls State of CuGeO3
}

M. Saint-Paul, G. Reményi, N. Hegmann, P. Monceau, G. Dhalenne, A. Revcolevschi

\section{- To cite this version:}

M. Saint-Paul, G. Reményi, N. Hegmann, P. Monceau, G. Dhalenne, et al.. Ultrasonic Study of Magnetoelastic Effects in the Spin-Peierls State of CuGeO3. Journal de Physique IV Proceedings, 1996, 06 (C8), pp.C8-539-C8-540. 10.1051/jp4:19968117 . jpa-00254547

\section{HAL Id: jpa-00254547 https://hal.science/jpa-00254547}

Submitted on 1 Jan 1996

HAL is a multi-disciplinary open access archive for the deposit and dissemination of scientific research documents, whether they are published or not. The documents may come from teaching and research institutions in France or abroad, or from public or private research centers.
L'archive ouverte pluridisciplinaire HAL, est destinée au dépôt et à la diffusion de documents scientifiques de niveau recherche, publiés ou non, émanant des établissements d'enseignement et de recherche français ou étrangers, des laboratoires publics ou privés. 


\title{
Ultrasonic Study of Magnetoelastic Effects in the Spin-Peierls State of $\mathrm{CuGeO}_{3}$
}

\author{
M. Saint-Paul, G. Reményi, N. Hegmann, P. Monceau, G. Dhalenne* and A. Revcolevschi* \\ CRTBT, Centre National de la Recherche Scientifique, BP. 166, 38042 Grenoble cedex 9, France \\ * Laboratoire de Chimie des Solides, Université Paris-Sud, Bâtiment 414, 91405 Orsay cedex, France
}

\begin{abstract}
The quasi-one-dimensional $\mathrm{CuGeO}_{3}$ compound is the first inorganic material to exhibit a spin-Peierls transition driven by the magnetoelastic interaction between antiferromagnetic chains and the phonon field which opens a finite energy gap in the spin excitation spectrum by the dimerization of the lattice. The anomalous elastic character of the spin-Peierls system is established by studying in a high magnetic field the propagation of longitudinal ultrasonic waves along the three crystalline axes. We have measured the longitudinal elastic constants $C_{11}, C_{22}$ and $C_{33}$ of $\mathrm{CuGeO}_{3}$ in magnetic fields up to 20 Teslas. The phase boundaries between the uniform (U), modulated (M) and dimerized (D) phases are associated to large anisotropic variations of the elastic constants. The temperature dependence of the three elastic constants exhibits a minimum at the U-D and $\mathrm{U}-\mathrm{M}$ phase boundaries. The field dependences of $\mathrm{C}_{22}$ and $\mathrm{C}_{33}$ are reported.
\end{abstract}

\section{INTRODUCTION}

The spin-Peierls (SP) transition is driven by the magnetoelastic interaction between the 1D antiferromagnetic chains and the $3 \mathrm{D}$ phonon field in the lattice which opens a finite gap in the spin excitation spectrum by the dimerization of the lattice [1]. $\mathrm{CuGeO}_{3}$ has been intensively studied and we present ultrasound measurements performed under high magnetic field up to 20 Teslas.

\section{Experimental results}

The $\mathrm{CuGeO} 3$ single crystalline samples were cut from a large crystal several $\mathrm{cm}$ long grown from the melt by a floating zone method associated with an image furnace[2]. The magnetic field was provided by a resistive Bitter coil which could be swept continuously from 0 to 20 Teslas. The magnetic field was parallel to the direction of the sound propagtion. The standard pulse echo tehnique was used with $\mathrm{LiNbO}_{3}$ tranducers and the sound velocity was measured by the phase coherent detection technique. The elastic constant $C$ is related to the sound velocity by the relation $\mathrm{C}=\mathrm{dV}^{2}$ where $\mathrm{d}$ is the mass density equal to $5.1 \mathrm{~g} / \mathrm{cm}^{3}$. At room temperature $\mathrm{C}_{11}, \mathrm{C}_{22}$ and $\mathrm{C}_{33}$ are equal to $7.2,4$ and $32 \times 10^{10} \mathrm{~N} / \mathrm{m}^{2}$ respetively corresponding to velocities of 3700,2600 and 8000 $\mathrm{m} / \mathrm{s}$. The temperature and magnetic field dependences have been reported in reference [3]. The magnetic field dependences of $\mathrm{C}_{22}$ and $\mathrm{C}_{33}$ measured at $4 \mathrm{~K}$ are shown in figure 1 . The D-M phase transition at $4 \mathrm{~K}$ is charaterized by a step-like decrease of $\mathrm{C}_{22}$ at the magnetic field $\mathrm{Hc}=12 \mathrm{~T}$, whereas $\mathrm{C}_{33}$ increases. The critical magnetic field $\mathrm{Hc}$ is slightly anisotropic because of the small $\mathrm{g}$ factor anisotopy, $\mathrm{g}$ is the electron gyromagnetic ratio[1]. The value $\mathrm{Hc}=12 \mathrm{~T}$, determined in figure $1 \mathrm{a}$ when magnetic field is applied along the crystallographic $\mathrm{b}$ axis, is in agreement with the $\mathrm{x}$-ray experiments[4]. $\mathrm{Hc}=13 \mathrm{~T}$ obtained when magnetic field is applied along the $\mathrm{c}$ axis is in agreement with the susceptibility measurements [5]. The sharp transition of $\mathrm{C}_{22}$ (sharpness $0.2 \mathrm{~T}$ ) is charateristic of a tirst order phase transition. Hysteresis in the variation of $\mathrm{C}_{33}$ when increasing and decreasing the magnetic field confirms the first order character of the transition. Theoretical approaches predict that, above the threshold field $\mathrm{Hc}$, the periodicity of the lattice modulation deviates from the commensurate wavevector[1]. Incommensurate lattice modulation has been observed in $\mathrm{CuGeO}_{3}$ in field exceeding $\mathrm{Hc}$ by a high resolution $\mathrm{X}$ ray diffraction experiment[4]. The chains are no longer dimerized but the interatomic spacing is modulated with a wavelength 
determined by the magnetic field. The present work confirms that the elastic properties of the compound is very sensitive to this structural D-M phase transition and the ultrasound technique is very useful to probe the order parameter[3]. Nevertheless the large anomalies of $C_{22}$ and $C_{33}$ at this transition are not yet explained and further theoretical work is necessary to elucidate such a behaviour. An incommensurate phase is characterized by an order parameter that is modulated with a wavelength incommensurate with the lattice periodicity. At high magnetic fields this modulation is sinusoidal. Close to the citical $\mathrm{Hc}$ field the modulation is no longer described by a plane wave, but an alternating sequence of commensurate regions and discommensurations in which the order parameter phase changes rapidly with respect to the underlying lattice[1].

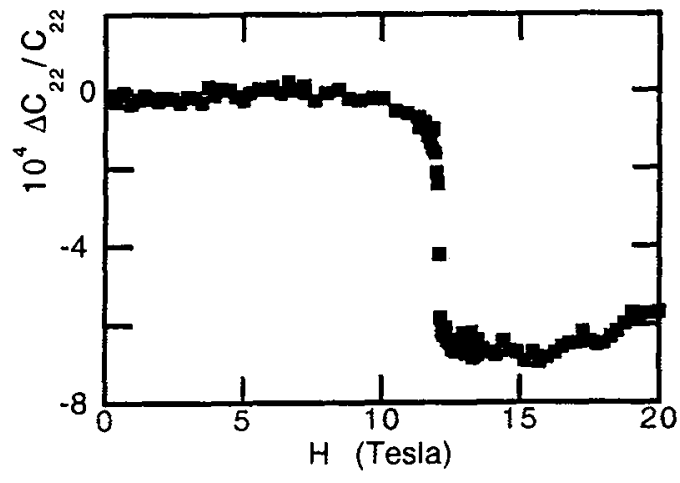

a)

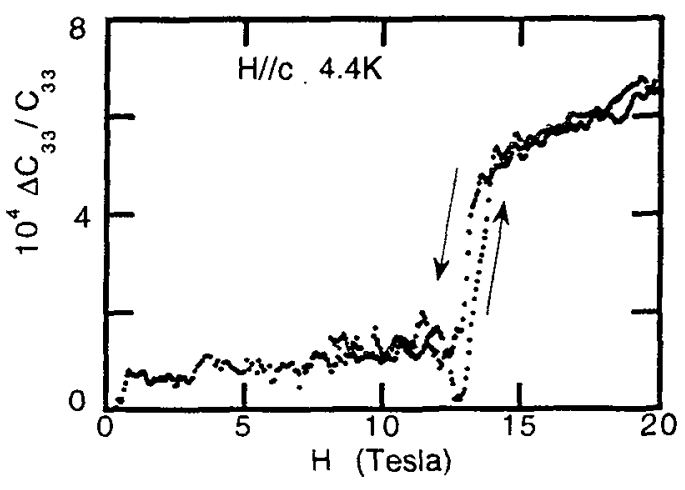

b)

Figure 1: Magnetic field dependence of the elastic constants $C_{22}$ (a) and $C_{33}$ (b) at $4 \mathrm{~K}$ : the magnetic field is along the $b$-axis (a) and the $c$-axis (b).

\section{References}

[1] For a review see J.W. Bray, L.V. Interrante, I.S. Jacobs and J. Bonner in Extended Linear Chain Compound edited by J.S. Miller (Plenum New York,1983) Vol3.

[2]A. Revcolevschi and R. Collonques C.R. Acad. Sci 266 1767(1969).

[3] M. Saint-Paul, G. Réményi, N. Hegman, P. Monceau, G. Dhalenne, and A. Revcolevschi Phys.Rev.B 52 (1995) 15298.

[4] V. Kiryukhin and B. Keimer, J.P. Hill and A. Vigliante Phys. Rev Lett 76 (1996) 4608.

[5] M. Hase I. Terasaki and K. Uchinorakura Phys. Rev. Lett. 70 (1993) 9616. 